J. Clin. Chem. Clin. Biochem.

Vol. 17, 1979, pp. 739-745

\title{
Eigenschaften und Bedeutung von Makro-Kreatinkinasen
}

\author{
Von W. Stein, J. Bohner, M. Eggstein \\ Medizinische Klinik Tübingen, Abteilung für Innere Medizin IV (Direktor Prof. Dr. M. Eggstein)
}

und

H. Lang

Biochemische Forschung, E. Merck Darmstadt

(Eingegangen am 18. Juli/4. Oktober 1979)

Dem Gedenken an Professor Dr. Gäbor Szäsz gewidmet

Zusammenfassung: Seren von siebẹn Patienten fielen durch einen ungewöhnlich hohen Kreatinkinase-MB/Gesamt-Kreatinkinase-Quotienten im Immuninhibitionstest auf. Die elektrophoretische Auftrennung der Isoenzyme der Kreatinkinase ergab in dieșen Fällen elne atypische Bande mit geringer elektrophoretischer Mobilität. Durch Auschlußchromatographie ließ sich in allen Seren Makro-Kreatinkinase nachweisen. Weitere chromatographische, elektrophoretische und immunologische Untersuchungen zeigten bei sechs Patienten, dạ diese Makro-Kreatinkinase aus an Immunglobulin $\mathrm{G}$ gebundenem Isoenzym Kreatinkinase-BB besteht.

\section{Properties and significance of macro-creatine kinases}

Summary: Sera from seven patients with an unusual high ratio of creatine kinase-MB versus total creatine kinase, as found in the immunoinhibition test, were investigated. In every case, the electrophoretic separation of the isoenzymes showed a slow moving band, and exclusion chromatography showed the presence of macro-creatine kinase. Further chromatographic, electrophoretic and immunological investigations indicated that the macro-creatine kinases in six cases are complexes of creatine kinase-BB linked to immunoglobulin G.

\section{Einleitung}

Seit der Einfüuhrung des Immuninhibitionstests (1) und des Immunpräzipitationstests (2) zur Isoenzymdiagnostik der Kreatinkinase (ATP:Kreatin:Phosphotransferase, EC 2.7.3.2) fanden sich - mit einer Frequenz von ungefähr 1:1000 - Patienten, die persistierende Aktivitäten des Isoenzyms Kreatinkinase-BB im Serum aufwiesen. Ein Zusammenhang mit einer Erkrankung war nicht nach. weisbar; daher wurde dieses Phänomen als "idiopathische Kreatinkinase-BB" bezeichnet $(3,4)$, Unabhängig davon wurden aufgrund elektrepheretischer Untersuchungen atypische Isoenzyme der Kreatinkinase (CK-AT) mitgeteilt $(5,6,7)$, die eine geringe elektrophoretische Mobilitặt und ein abnormes Elutionsprofil bei der Isoenzym- bestimmung auf Anionenaustauschern zeigten. Die Isoenzymbestimmung mit Ionenaustauschchromatographie und dem Immuninhibitionstest täuschten bei diesen Patientenseren hohe Kreatinkinase-MB-Werte vor. Im Rahmen der Diagnostik fielen sieben Patienten mit normaler bis deutlich erhöhter Gesamt-Kreatinkinase und einem ungewöhnlich hohen Anteil (Quotient 0,76 bis 1,50 ) der Kreatinkinase-MB im Immuninhibitionstest auf. Bemerkenswerterweise persistierten diese Enzymaktivitäten im weiteren Krankheitsverlauf.

Die weiteren Untersuchungen zeigten, daß sowohl die "idiopathische Kreatinkinase-BB" als auch das atypische Issoenzym "CK-AT" der Literatur durch die Existenz von Makro-Kreatinkinasen erklärt werden können $(8,9,10)$. 


\section{Material und Methoden}

Alle Seren wurden möglichst innerhalb von $48 \mathrm{~h}$ nach Blutentnahme analysiert oder nach Zusatz von 2-Mercaptoe thanol $(20 \mathrm{mmol} / \mathrm{l})$ bei $-18^{\circ} \mathrm{C}$ aufbewahrt.

\section{Enzymbestimmungen}

Aktivitätsbestimmungen der Kreatinkinase erfolgten mit der durch N-Acetyl-cystein aktivierten Methode (Boehringer, Mannheim, Nr. 126357). Die Kreatinkinase-Aktivität der Chromatographie-Fraktionen wurde am aca von DuPont (DuPont de Nemours, Wilmington, Delaware, USA) gemessen; dabei wurden Probenmengen von 400,500 oder $1000 \mu \mathrm{zu}$ sammen mit der entsprechenden Menge Wasser manuell unter Umgehung der Füllstation direkt in den "Testpack" injiziert.

\section{Ausschlußchromatographie}

Jeweils $200 \mu \mathrm{l}$ Serum wurden an Säulen mit Sephadex G-200 $(21 \times 0,9 \mathrm{~cm}$, Pharmacia, Uppsala, Schweden) und Sephadex G-200 sf $(22 \times 0,9 \mathrm{~cm}$ bzw. $55 \times 0,9 \mathrm{~cm})$ als stationärer Phase chromatographiert. Als mobile Phase diente ein Puffer aus $50 \mathrm{mmol} / 1$ Tris(hydroxymethyl)-aminomethan (E. ${ }^{\circ}$ Merck, Darmstadt, Nr. 8387), 20 mmol/1 N-Acetyl-cystein (Merck Nr. 12422) und $2 \mathrm{mmol} / 1$ EDTA-di-Kaliumsalz (Riedel-de Haën, Seelze, Nr. 64072) von pH 7,0. Die Molekulargewichte der Kreatinkinasen ließen sich aus den $\mathrm{K}_{\mathrm{ar}}$ Werten der Trennung an Sephadex G-200 sf $(55 \times 0,9 \mathrm{~cm})$ abschätzen (11).

\section{Ionenaustauschchromatographie}

$500 \mu$ l oder $1000 \mu$ l Serum wurden auf DEAE-Sephadex A-50 Fertigsäulen $(15 \times 0,8 \mathrm{~cm}$, Betthöhe circa $5 \mathrm{~cm}$, Roche Diagnostics, Nutley, N.J., USA) aufgetragen, mit je $8 \mathrm{ml}$ Trispuffer $(50 \mathrm{mmol} / \mathrm{l}) \mathrm{im} \mathrm{NaCl}$-Stufengradienten von $100 \mathrm{mmol} / \mathrm{l}$ (pH 8,0), $200 \mathrm{mmol} / \mathrm{l}(\mathrm{pH} 8,0)$ und $500 \mathrm{mmol} / 1(\mathrm{pH} \mathrm{7,0)} \mathrm{eluiert}$ und in Fraktionen von $1 \mathrm{ml}$ gesammelt. Die $1 \mathrm{ml}$-Fraktionen der Eluate wurden zu den Hauptfraktionen A, B und C gepoolt und konzentriert (Amicon Konzentrator B15, Amicon GmbH, Witten).

\section{Elektrophorese}

Die Isoenzyme der Kreatinkinase wurden $150 \mathrm{~min}$ bei $4 \mathrm{~V} / \mathrm{cm}$ und $15{ }^{\circ} \mathrm{C}$ in Agarose-Gel $(10 \mathrm{~g} / \mathrm{l})$ aufgetrennt (Multiphor, LKB, Bromma, Schweden). Trispuffer (pH 6,9), Reagenzien zur Darstellung der Isoenzyme und Kreatinkinase-Standard stammten von Sigma Chemie, München (Nr. 715-EP).

Immunologische Untersuchungen

Inhibitionstest

Die Aktivität der Kreatinkinase-B-Unterheinheit im Serum wurde mit dem Merck-1-Test, CK-MB (Nr. 14300 u. Nr. 14326) bestimmt (1).

\section{Präzipitationstest}

Die Differenzierung der Kreatinkinase-Isoenzyme erfolgte mit präzipitierenden Antikörpern vom Hammel gegen KreatinkinaseMM und Kreatinkinase-BB (Merck Nr. 11642 und Nr. 11643) entsprechend der Vorschrift (2).

\section{Doppeldiffusions-Methode (Ouchterlony)}

Zur Charakterisierung Kreatinkinase-bindender Immunglobuline diente die Ouchterlony-Technik in Agarosegel $(10 \mathrm{~g} / \mathrm{l})$. Nach Ausbildung der Präzipitatsicheln durch spezifische Antisera gegen Immunglobuline vom Menschen (Anti-IgG Nr. 16577, Anti-IgA Nr. 5263, Anti-IgM Nr. 191277 der Behringwerke, Marburg und Anti-IgG Nr. 13198, Anti-IgA Nr. 23208, Anti-IgM Mr. 33218 von Molter, Heidelberg) und Staphylokokkenprotein A (Nr. P 8143, Sigma Chemie, München) wurden die Agarplatten gewässert und die Kreatinkinase-Aktivität analog der Elektrophorese-Technik nachgewiesen.

\section{Quantitative Präzipitation der Kreatinkinase-Immunglobulin.} Komplexe

Steigende Mengen Kreatinkinase-freier Antiseren (Behringwerke) oder Staphylokokkenprotein A (Sigma Chemie) wurden den Patientenseren zugesetzt. Die Ansä̈tze wurden wie im Präzipitationstest zur Isoenzymbestimmung (2) behandelt.
Bindung von Kreatinkinase-Isoenzymen im Makro-Kreatinkinase-Serum

Durch Ionenaustauschchromatographie wurden die KreatinkinaseIsoenzyme aus Seren von Patienten mit Muskeltrauma (KreatinkinaseMM), Myocardinfarkt (Kreatinkinase-MM, Kreatinkinase-MB) sowie aus den Makro-Kreatinkinase-Seren Doe. und Far. (KreatinkinaseBB) isoliert, elektrophoretisch auf die Isoenzymzusammensetzung geprüft und innerhalb von $12 \mathrm{~h}$ verarbeitet. Serum Doe. (3 ml) wurde durch Chromatographie an Sephadex G-200 $(90 \times 2,5 \mathrm{~cm})$ bei pH 3,2 (Glycinpuffer, $50 \mathrm{mmol} / \mathrm{l})$ Kreatinkinase-frei gewonnen, mit Trispuffer $(50 \mathrm{mmol} / \mathrm{l})$ neutralisiert, auf $3 \mathrm{ml}$ eingeengt und auf Kreatinkinase-Aktivität geprüft. Jeweils $200 \mu$ dieses Kreatinkinase-freien Serums wurden mit $100 \mu \mathrm{l}$ einer Isoenzy mpräparation versetzt, $5 \mathrm{~h}$ (KreatinkinaseMB zusätżlich $18 \mathrm{~h}$ ) bei $22^{\circ} \mathrm{C}$ inkubiert und an Sephadex G-200 sf $(22 \times 0,9 \mathrm{~cm})$ chromatographiert, um Makro-Kreatinkinase nachz̈uweisen.

\section{Ergebnisse}

\section{Im munologische Isoenzy m bestimmungen}

Die Ergebnisse der beiden immunologischen Kreatinkinase-Isoenzym-Bestimmungen sind in Tab. 1 zusammengefaßt. In sechs der sieben Patientenseren waren außergewöhnlich hohe Anteile von Kreatinkinase-BB (Quotient 0,31 bis 0,91) an der Kreatinkinase-Gesamtaktivität nachweisbar. Nach der in l.c. (2) aufgeführten Formel (Kreatinkinase-MB = Gesamt-Kreatinkinase - (Kreatinkinase$\mathrm{MM}+$ Kreatinkinase-BB) errechneten sich auch im Immunpräzipations-Test beträchtliche Anteile an Kreatinkinase-MB (Quotient bis 0,38 im Serum Ung.). Abweichend verhielt sich hier das Serum Hai. (Tab. 1, Pat. 3); seine Isoenzym-Zusammensetzung war immunologisch nicht bestimmbar, da es weder mit Anti-KreatinkinaseBB- noch mit Anti-Kreatinkinase-MM-Serum réagierte.

\section{Ausschlußchromatographie}

Die Abbildungen 1a-c zeigen die Chromatogramme nach Auftrennung der Patientenseren an Sephadex. Aufgrund ihrer geringen Elutionsvolumina konnten in allen sieben Seren Makro-Kreatinkinasen nachgewiesen werden. Neben großmolekularer Kreatinkinase (Peak M) war regelmäßig Kreatinkinase mit "normalem" Molekulargewicht (Peak N) vorhanden. Deren Anteil variierte von Patient zu Patient und betrug im Serum Far. (Abb. 1, c) rund 0,50, im Serum Doe. weniger als 0,10. Nur Säulen $(55 \times 0,9 \mathrm{~cm}) \mathrm{mit}$ Sephadex G-200 sf als stationärer Phase erzielten basisliniengetrennte Kreatinkinase-Aktivitätspeaks. Dafür waren Treninzeiten von etwa $24 \mathrm{~h}$ erforderlich. Ein auf $22 \times 0,9$ $\mathrm{cm}$ reduziertes Bettvolumen ergab noch befriedigende Trennleistungen; doch benötigte die Chromatographie weiterhin einige Stunden (Abb. 1, c). Erst Sephadex G:200:(21 X $0,9 \mathrm{~cm}$ ) ermöglichte Auftrennungen in weniger als einer Stun'de (Abb. 1 b). Die Auflösung der beiden KreatinkinaseFraktionen war zwar reduziert, für den Nachwieis von MakroKreatinkinase neben normaler Kreatinkinase jedoch ausreichend. 
Tab. 1. Patienten mit Makro-Kreatinkinase: Diagnosen und Ergebnisse der immunologischen Isoenzymbestimmungen.

\begin{tabular}{|c|c|c|c|c|c|c|c|c|}
\hline \multirow[t]{3}{*}{ Patient } & \multirow[t]{3}{*}{$\begin{array}{l}\text { Geschlecht, } \\
\text { Alter (a) }\end{array}$} & \multirow[t]{3}{*}{ Diagnosen } & \multirow{3}{*}{$\begin{array}{l}\text { Gesamt- } \\
\text { Kreatin- } \\
\text { kinase }\end{array}$} & \multicolumn{2}{|c|}{$\begin{array}{l}\text { Kreatinkinase-MB- } \\
\text { Nachweis durch Im- } \\
\text { muninhibition }{ }^{+}\end{array}$} & \multicolumn{3}{|c|}{$\begin{array}{l}\text { Anteil der Kreatinkinase-Isoenzyme an } \\
\text { der Gesamt-Krcatinkinase nach Immun- } \\
\text { präzipitation }\end{array}$} \\
\hline & & & & & & $\begin{array}{l}\text { Kreatin- } \\
\text { kinase-MM }\end{array}$ & $\begin{array}{l}\text { Kreatin- } \\
\text { kinase-BB }\end{array}$ & Kontrolle ${ }^{+++}$ \\
\hline & & & & $(U / 1)$ & Quotient & Quotient & Quotient & \\
\hline 1. Ung., E. & 9,45 & $\begin{array}{l}\text { Urticaria } \\
\text { pigmentosa }\end{array}$ & 91 & 71 & 0,78 & 0,0 & 0,62 & pos. \\
\hline 2. Rei., G. & 9,73 & Coloncarcinom & 106 & 123 & 1,16 & 0,18 & 0,67 & pos. \\
\hline 3. Hai., E. & 8,74 & Coloncarcinom & 152 & 172 & 1.13 & 1,10 & 1,10 & neg.! \\
\hline 4. Doe., E. & १, 59 & Myocardinfarkt & 131 & 120 & 0,92 & 0.06 & 0,91 & pos. \\
\hline 5. Pfe., H. & 9,45 & Colitis ulcerosa & 76 & 73 & 0,96 & 0,11 & 0,79 & - \\
\hline 6. Far., R. & 8,77 & $\begin{array}{l}\text { Myocardinfarkt, } \\
\text { Apoplekt. Insult }\end{array}$ & 82 & 62 & 0.76 & 0,50 & 0,31 & pos. \\
\hline 7. Dob., L. & 9.66 & $\begin{array}{l}\text { Koronare Herz- } \\
\text { Krankheit }\end{array}$ & 50 & 75 & 1,50 & 0,0 & 0,80 & pos. \\
\hline
\end{tabular}

+ Inhibitions Test (Merck-1-Test CK-MB, No. 14 300)

++ Präzipitations Test (Merck No. 11642 und No. 11 643)

+++ Positive Kontrolle: Zugabe von Anti-Kreatinkinase-BB- und Anti-Kreatinkinase-MM-Serum führt zur vollständigen Präzipitation der Kreatinkinase-Aktivität.

Negative Kontrolle: Gemeinsame Zugabe von Anti-Kreatinkinase-BB und Anti-Kreatinkinase-MM bewirkt keine Präzipitation.
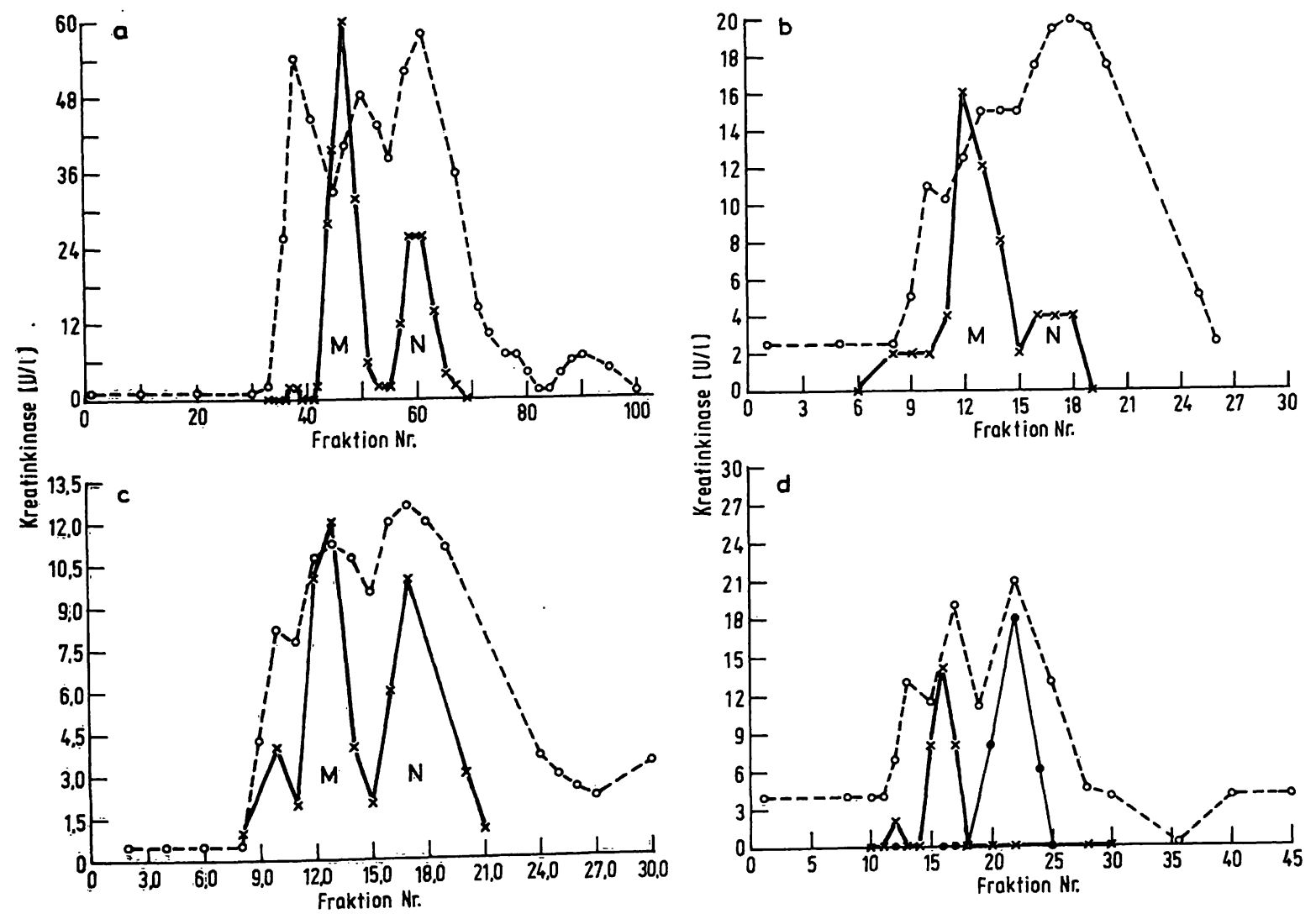

Abb. 1. Chromatographie von $200 \mu \mathrm{l}$ Serum an Sephadex. $\mathrm{x}-\mathrm{x}$ : Kreatinkinase-Aktivität. M: Makro-Kreatinkinase, N: normale Kreatinkinase. 0--0--o: Absorbanz bei $254 \mathrm{~nm}$.
a) Serum Rei. Sephadex G-200 sf $(55 \times 0,9 \mathrm{~cm})$
b) Serum Ung. Sephadex G-200 $(21 \times 0,9 \mathrm{~cm})$
c) Serum Far. Sephadex G-200 sf $(22 \times 0,9 \mathrm{~cm})$
d) Rekombinationsversuch: $x-x$ : mit Kreatinkinase-BB
- mit Kreatinkinase-MB oder Kreatinkinase-MM 
Tab. 2. Abschätzung der Molekulargewichte von MakroKreatinkinasen nach Chromatographie an Sephadex G-200 sf. Säule: $55 \times 0,9 \mathrm{~cm}, \mathrm{~V}_{0}: 17,5 \mathrm{ml}, \mathrm{V}_{\mathrm{t}}: 32,4 \mathrm{ml}$.

\begin{tabular}{|c|c|c|c|c|}
\hline Patient & $\mathrm{V}_{\mathrm{e}}$ & $\mathrm{K}_{\mathrm{av}}$-Wert & $M_{\mathrm{r}}$ & \\
\hline Ung., E. & $\begin{array}{l}19,5 \\
23,9\end{array}$ & $\begin{array}{l}0,14 \\
0,43\end{array}$ & $\begin{array}{r}350000 \\
80000\end{array}$ & $\begin{array}{l}\text { Makro-CK } \\
\text { Kreatin- } \\
\text { kinase }\end{array}$ \\
\hline Rei., G. & $\begin{array}{l}20,1 \\
24,1\end{array}$ & $\begin{array}{l}0,18 \\
0,44\end{array}$ & $\begin{array}{r}300000 \\
78000\end{array}$ & $\begin{array}{l}\text { Makro-CK } \\
\text { Kreatin- } \\
\text { kinase }\end{array}$ \\
\hline Hai., E. & $\begin{array}{l}19,2 \\
24\end{array}$ & $\begin{array}{l}0,11 \\
0,43\end{array}$ & $\begin{array}{r}350000 \\
80000\end{array}$ & $\begin{array}{l}\text { Makro-CK } \\
\text { Kreatin- } \\
\text { kinase }\end{array}$ \\
\hline Doe., E. & $\begin{array}{l}19,5 \\
18,0 \\
24\end{array}$ & $\begin{array}{l}0,13 \\
0,04 \\
0,42\end{array}$ & $\begin{array}{r}350000 \\
650000 \\
85000\end{array}$ & $\begin{array}{l}\text { Makro-CK } \\
\text { Kreatin- } \\
\text { kinase }\end{array}$ \\
\hline \multicolumn{5}{|c|}{ Referenzproteine } \\
\hline $\begin{array}{l}\text { Albumin } \\
\beta \text {-Lipo- } \\
\text { protein }\end{array}$ & $\begin{array}{l}24,5 \\
20,3\end{array}$ & $\begin{array}{l}0,48 \\
0,18\end{array}$ & $\begin{array}{r}65000 \\
260000\end{array}$ & \\
\hline $\begin{array}{l}\text { Ig G } \\
\alpha_{2-} \\
\text { Makro- } \\
\text { globulin }\end{array}$ & $\begin{array}{l}22 \\
17,6\end{array}$ & $\begin{array}{l}0,30 \\
0,01\end{array}$ & $\begin{array}{r}160000 \\
>700000\end{array}$ & \\
\hline
\end{tabular}

Eine Abschätzung der Molekulargewichte von MakroKreatinkinasen ist aus den Chromatogrammen möglich. Diese Ergebnisse sind in Tabelle 2 zusammengefaßt.

\section{Ionenaustausch chromatographie}

In der hier benutzten Ionenaustausch-Chromatographie wurden Kreatinkinase-MM in Fraktion A, Kreatinkinase$M B$ in Fraktion B und Kreatinkinase-BB in Fraktion C eluiert. In Abbildung 2 sind charakteristische Chromatogramme von Makro-Kreatinkinase-Seren dargestellt. Überraschend fand sich in allen drei Fraktionen KreatinkinaseAktivität. Allerdings unterschieden sich die Elutionsprofile von Serum zu Serum. Nahezu die gesamte Kreatinkinase-Aktivität des Serums Hai. erschien in Fraktion A (Abb. 2c), während die übrigen Seren beträchtliche Aktivitäten in den Fraktionen B und $C$ aufwiesen (Abb. 2a und 2b).

In Abhängigkeit von der Reaktionszeit zwischen Serum und Ionenaustauscher änderten sich die KreatinkinaseElutionsprofile. Bei längerer Einwirkdauer des Anionenaustauschers fiel eine Aktivitätszunahme in Fraktion C auf Kosten der Fraktion A auf. Abbildung 3 zeigt dieses bemerkenswerte Verhalten am Beispiel der Seren Doe. und Ung. Lediglich für das Makro-Kreatinkinase-Serum Hai. war dieser Effekt nicht nachweisbar.

\section{Elektrophorese}

Abbildung 4 zeigt die Elektropherogramme der Kreatinkinase-Isoenzyme. Charakteristisch für alle Makro-Kreatin-
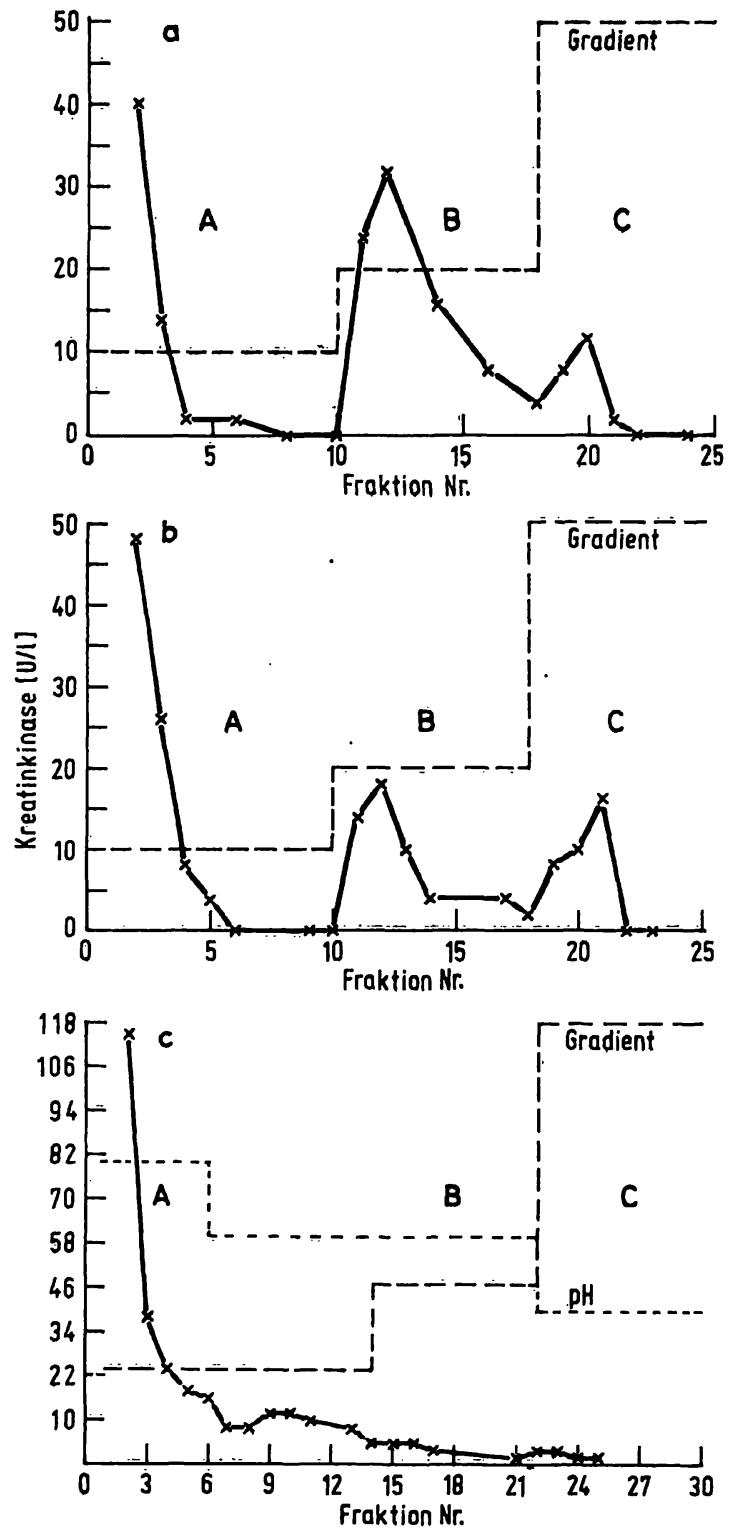

Abb. 2. Chromatographie an DEAE-Sephadex A-50. $x-x-x$ : Kreatinkinase-Aktivität

- - : Verlauf des Stufengradienten: 100, 200 und $500 \mathrm{mmol} / 1 \mathrm{NaCl}$ in $50 \mathrm{mmol} / \mathrm{l}$ Tris Puffer. : Verlauf des pH Wertes während des Gradienten.

a) Serum Pfe.

b) Serum Rei.

c) Serum Hai.

kinase-Seren waren atypische Fraktionen zwischen den Isoenzymen Kreatinkinase-MM und Kreatinkinase-MB im Bereich der Auftragsstelle. Zusätzlich ließen sich wechselnde Anteile von Kreatinkinase-MM darstellen; im Serum Far. (Makro-Kreatinkinase und Herzinfarkt) fand sich eine diskrete Kreatinkinase-MB-Bande. In keinem dieser Seren war elektrophoretisch jedoch KreatinkinaseBB nachzuweisen.

Erst die elektrophoretische Analyse der Fraktionen A, B und $\mathrm{C}$ der Ionenaustausch-Chromatographie $(\mathrm{Abb}, 2)$ zeigte, daß die Fraktion $C$ ausschließlich aus Kreatin. kinase-BB bestand, während die. Fraktionen $A$ und $B$ überwiegend die atypische Kreatinkinase enthielten. 

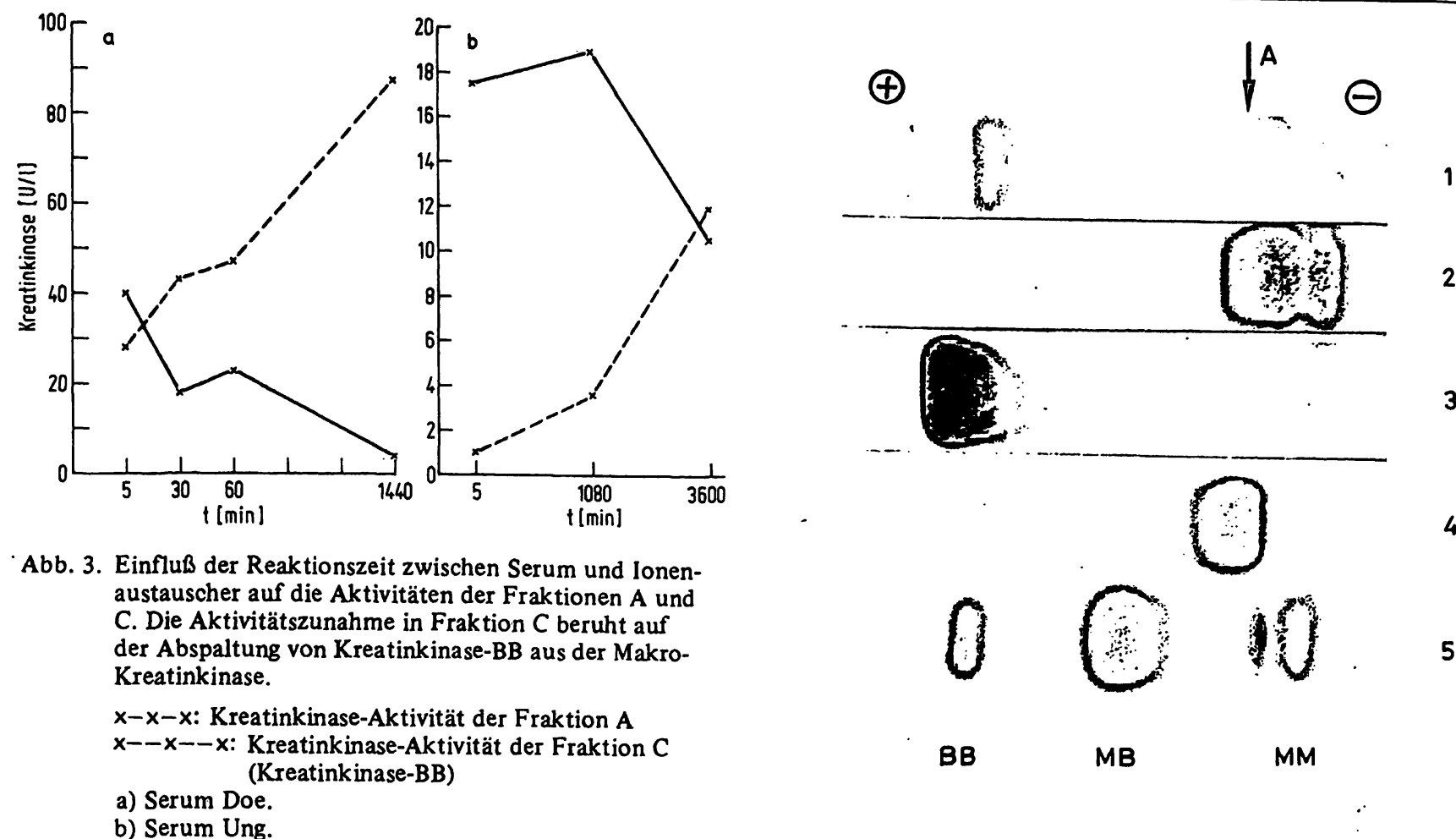

Nachweis von Kreatinkinase-bindenden Immunglobulinen

Mit schwerkettenspezifischen Antiseren gegen HumanIgG ließ sich im Serum Doe. mit der Ouchterlony-Technik (Tab. 3) und in der quantitativen Immunpräzipitation Immunglobulin $\mathrm{G}$ als makromolekularer Bindungspartner der Kreatinkinase-BB ermitteln (10). Auch in der Präzipitatsichel, die sich zwischen dem Serum Rei. und AntiIgG-Serum ausgebildet hatte, lag Kreatinkinase-Aktivität vor (Tab. 3). Bei den übrigen Seren waren die Präzipitatsicheln gegen IgG-, IgA- und IgM-Globuline ohne Kreatinkinase -Aktivität. Mit Staphylokokkenprotein A (12) ließ sich in beiden Techniken - außer bei Serum Hai. - IgG als Bestandteil der Makro-Kreatinkinase nachweisen. Die Präżipitationskurven zweier Patientenseren sind in Abbildung 5 dargestellt.

Abb. 4. Elektrophoretische Auftrennung der KreatinkinaseIsoenzyme auf Agarosegel ( $10 \mathrm{~g} / \mathrm{l})$.

1: Serum Far., Fraktion $C$ nach Ionenaustausch (Kreatinkinase-BB).

2: Serum Far.

3: Serum Doe., Fraktion $C$ nach Ionenaustausch (Kreatinkinase-BB).

4: Serum Doe.

5: Standard

6: Sțandard

7: Serum Hai.

8: Serum Ung.

9: Serum Rei.

10: Serum Dob.

11: Standard

12: Serum Pfe.

13: Standard

14: Serum Ung.

15: Serum Ung., Fraktion $C$ nach lonenaustausch (Kreatinkinase-BB).

A: Auftragsstelle
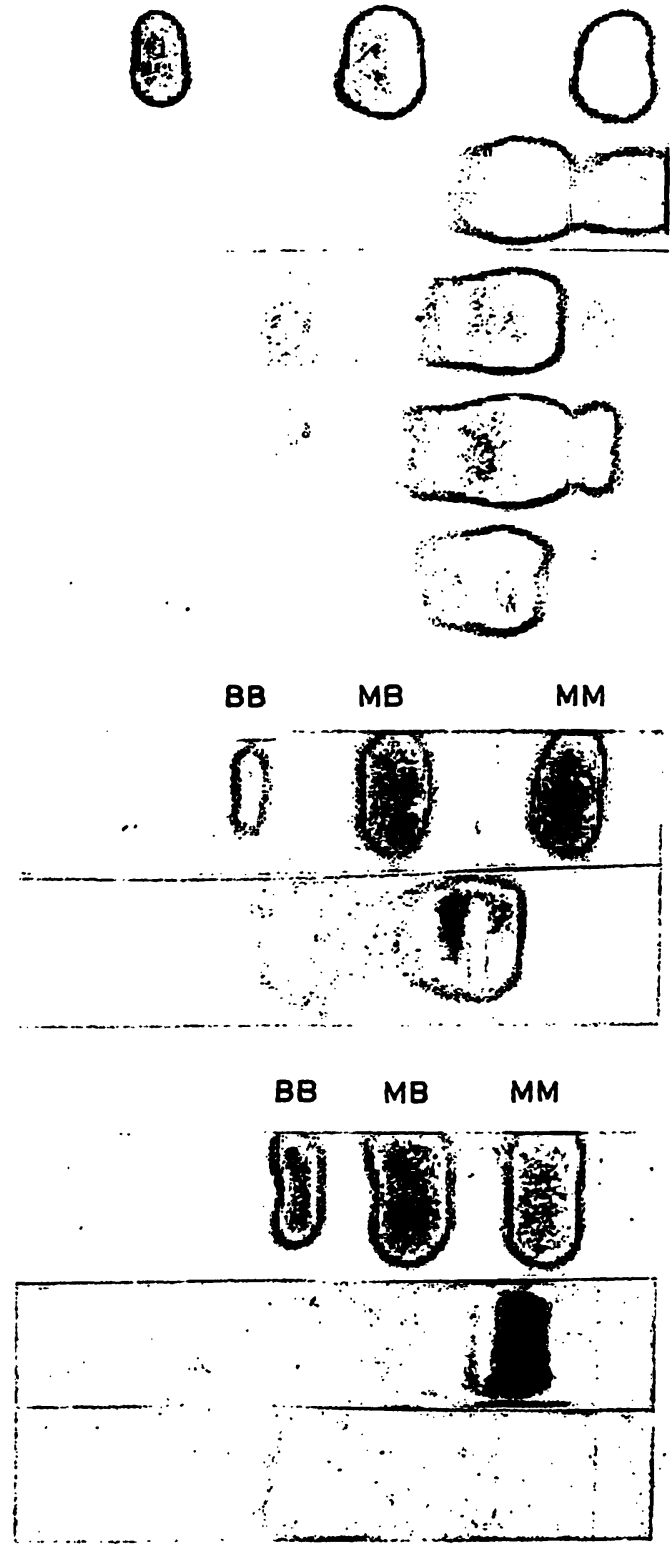
Tab. 3. Nachweis von IgG als Bestand teil von Makro-Kreatinkinasen in der Doppeldiffusions-Methode (Ouchterlony). Im positiven Fall findet sich Kreatinkinase-Aktivität in der Präzipitationssichel.

\begin{tabular}{llll}
\hline Patient & $\begin{array}{l}\text { Anti-lg G } \\
\text { (Behring) }\end{array}$ & $\begin{array}{l}\text { Anti-lg G } \\
\text { (Molter) }\end{array}$ & $\begin{array}{l}\text { Staphylo- } \\
\text { kokken } \\
\text { Protein A }\end{array}$ \\
\hline
\end{tabular}

1. Ung... E.

2. Rei.. G.

3. Hai.. E.

4. Doe., E.

5. Pfe.. $H$.

6. Far., $R$.

7. Dob., L.
$+$

$+$

$-$

$+$

$+$

$+$

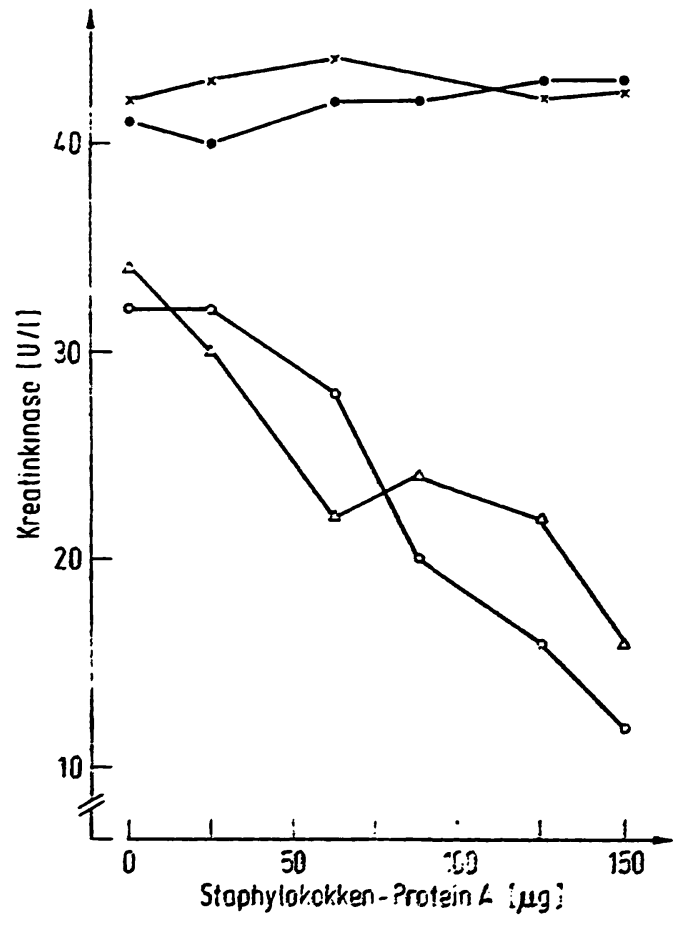

Abb. 5. Präzipitation skurven. Abnahme der Kreatink.inaseAktivität im Überstand nach Präzipitation der IgCgebundenen Kreatinkinase durch StaphylokokkenProtein A.

ンーンーこ: Serum Doe.

L-L-L: Serum Rei.

- - - Serum eines Patienten mit Myositis,

x.-y.-x: Serum eines Patienten mit Myokardinfarkt.

Die Ausschluß-Chromatographie nach Rekombination yon Kreatinkinase-freiem Serum mit Isoenzympräparationen 'reigt Abbildung / d. Nur das Isoenzym Kreatinkinase-BB bjidet mit dem Serum Doe. Makro-Kreatinkinase. Mit Kreatinkinase-MM und Kreatinkinase-MB entstand innerhalb yon $5 \mathrm{~h}$ b\%w. $18 \mathrm{~h}$ keine Makro:K Kẹtinkinase.

\section{Diskussion}

Das Isoenzym Kreatinkinasc-BB (brain type creatine kinase) kommt im Scrum nur in Spuren vor (13) und wird mit den üblichen Methoden nicht erfaßt. Vereinzelt wurde über erhöhte Kreatinkinase-BB-Aktivitüten in Patientenseren berichtet. Ihre biologische Bedeutung blieb unerkannt. In der "Diagnostik" zeigten die Seren mit idiopathischer Kreatinkinase.BB holie Kreatinkinase-MBWerte im Immuninhibitionstest und erhöhte KreatinkinaseBB-Aktivitäten im Präzipitationstest. Die vermutete Koinzidenz von idiopathischer Kreatinkinase-BB oder atypischer Kreatinkinase mit kardiologischen Erkrankungen $(3,5,14)$ war wegen der gezielten Isoenzymbestimmung bei diesem Patientengut unseres Erachtens eher zufällig. Gemeinsam war diesen Patienten höheres Lebensalter, Uberwiegen des weiblichen Geschlechts und die Persistenz der Kreatinkinase-Aktivitäten. Die erhöhte Gesamt-Kreatinkinase und der abnorme Kreatinkinase-MB/GesamtKreatinkinase-Quotient ließen sich bei der Patientin Ung. 15 Monate und bei der Patientin Doe. 9 Monate zurückverfolgen.

Die Diagnose "Makro-Kreatinkinase-Ämie" ist mit der beschriebenen Ausschlußchromatographie innerhalb von 2 Stunden möglich. Die Molekulargewichte der Makrokreatinkinasen unserer Patientenseren lagen um 350 000; damit war das Vorliegen von mitochondrialer Kreatinkinase (CK-MiMi) (15) oder Adenylatkinase (ATP:AMP Phosphotransferase; EC 2.7.4.3) ausgeschlossen. Im Serum Doe. fanden sich konstant zwei Aktivitätsgipfel, die Molekulargewichten von 350000 und 650000 entsprachen.

Auch elektrophoretisch boten die Makro-KreatinkinaseSeren ein einheitliches Bild. Hier imponierte eine atypische Aktivitätsbande zwischen den Isoenzymen KreatinkinaseMM und Kreatinkinase-MB.

Sax et al. (5) sowie Chemnitz et al. (14) beschrieben ähnliche elektrophoretische Bilder, wiesen jedoch keine makromolckulare Kreatinkinase nach. Urdal et al. (8) und eigene Untersuchungen $(9,10)$ zeigten erstmals die Zusammenhänge zwischen "atypischer Kreatinkinase" in der Elektrophorese, makromolekularer Enzymform und persistierend erhöhtẹr Enzymaktivität.

Weitere Eigenschaften der Makro-Kreatinkinase konnten durch die Chromatographie an Anionenaustauschern erfaßt werden: Makro-Kreatinkinase-Moleküle dissozilerten wählirend der Chromatographịe unnd fụhrtẹ zum Auftroten des I soenzyms Kreatinkinase-BB. Dieser zeitablängige Yorgang (Abb. 3) dürfie aụf Interaktionen zwischen Makro-Kreatinkinase und Ionenạustauscher beruhen und ist eine Ursache von Fehlinternre tatipnen chromalogruphi. scher Isoenzymhestimmungen.

Der Nach weis von I mmunglabulin als Komponente der Makro-Kreatinkinase crfolgte hicr durch Präzipilatjong. methoden, die anch dic Alfklüruns unn Makrfo-Anuylasou (16) und Makmfinimen Her alkalisclien Bhosnhatasen (17) 
als Immunglobulin-Enzym-Komplexe ermöglichten. In den Seren Doe. und Rei. präzipitierte die Makro-Kreatinkinase mit Anti-IgG-Seren. Von sechs Makro-Kreatinkinase-Seren ließ sich die Kreatinkinase-Aktivität durch Staphylokokken-Protein A, das gegen den Fc-Teil von IgG gerichtet ist, fällen. Ein Ausbleiben der Präzipitation ((18), Serum Hai.) schließt die Existenz eines Kreatinkinase-Immunglobulinkomplexes nicht zwangsläufig aus; es ist denkbar, daß vorliegende Immunkomplexe die Reaktion mit spezifischen Antiseren verhindern. Eine Dissoziation von Makro-Kreatinkinase während der Fällungsversuche konnte durch Analyse der Überstände ausgeschlossen werden.

In freier Form besitzt Kreatinkinase-BB von allen Isoenzymen die kürzeste Halbwertszeit (19). Die Bindung von Kreatinkinase-BB an Immunglobuline verändert offenbar den Katabolismus des Enzyms wesentlich und kann die Persistenz der Enzymaktivitäten im Blut der Patienten erklären.

An einem Makro-Kreatinkinase-Serum wurde nachgewiesen, daß dessen Immunglobuline nur Kreatinkinase-BB, nicht dagegen Kreatinkinase-MM oder Kreatinkinase-MB binden (Abb. 1d). Unterschiedliche Affinität und Spezifität der Enzym-Immunglobulin-Bindung lassen ein weites Spektrum physikochemischer, immunologischer und kinetischer Eigenschaften von Makro-KreatinkinaseKomplexen erwarten. Mit methodischen Störungen bei der Analytik von Kreatinkinase-Isoenzymen muß bei Anwesenheit von Makro-Kreatinkinase gerechnet werden: In den hier untersuchten Seren von sieben Patienten führte die Makro-Kreatinkinase-BB zu erhöhten und persistierenden "Kreatinkinase-MB-Werten" bei den immunologischen und chromatographischen Isoenzymbestimmungen und zu einer atypischen Kreatinkinase-Bande in der Elektrophorese.

\section{Danksagung}

Wir danken Herrn Dr. Bottesch (Hoffmann-LaRoche AG, Grenzach) für Ionenaustauschersäulen, Herrn Dr. Münscher (Behringwerke, Marburg) für Kreatinkinase-freie Antiimmunglobulinseren und Herrn Prof. Dr. Rick für die. Überlassung eines Makro-Kreatinkinase-Serums.

\section{Literatur}

1. Würzburg, U., Hennrich, N., Lang, H., Priellwitz, W., Neumeier, D. \& Knedel, M. (1976), Klin. Wochenschr. 54, $357-360$.

2. Würzburg, U., Hennrich, N., Ort, H.-D., Lang, H., Prellwitz, W., Neumeier, D., Knedel, M. \& Rick, W. (1977), J. Clin. Chem. Clin. Biochem. 15, 131-137.

3. Lang, H., Würzburg, U., Neumeier, D., Knedel, M., Prellwitz, W., Kattermann, R., Schlebusch, H. \& Schürmann, J. (1978) Klin. Wochenschr. 56, 641-646.

4. Sieg, J., Gauchel, F. D. \& Herrschaft, H. (1977), Dtsch. Med. Wochenschr. 102, 1647-1649.

5. Sax, S. M., Moore, J. J., Giegel, J. L. \& Welsh, M. (1976) Clin. Chem. 22, 87-91 und (1979) Clin. Chem. 25, 535-541.

6. Ljungdahl, L. \& Gerhardt, W. (1978) Clin. Chem. 24, 832-834.

7. Fiolet, J. W. T., Willebrands, A. F., Lie, K. I. \& Ter Welle,

H. F. (1977) Clin. Chim. Acta 80, 23-35.

8. Urdal, P. \& Landaas, S. (1979) Clin. Chem. 25, 461-465.

9. Stein, W. \& Bohner, J. (1979) Clin. Chem. 25, 1513-1514.

10. Bohner, J., Stein, W., Kuhlmann, E. \& Eggstein, M. (1979) Clin. Chim. Acta 97, 83-88.
11. Sephadex, Gelfiltration in theory and practice (1973) Pharmacia, Uppsala, Schweden (Firmenschrift).

12. Grov, A., Oeding, P., Myklestod, B. \& Austen, J. (1970) Acta Pathol. Microbiol. Scand. 78 B, 106-111.

13. Jung, K., Neumann, R., Cobet, G., Nugel, E. \& Egger, E. (1979) Clin. Chim. Acta 91, 165-168.

14. Chemnitz, G., Jockers-Wretou, G. E., Schmidt, E., Schmidt, F. W. \& Lobers, J. (1979) J. Clin. Chem. Clin. Biochem. 17 , 146.

15. Deus, B., Schiessel, C., Blum, H. E. \& Gerok, W. (1979) Hoppe-Seyler's Z. Physiol. Chem. 360, 1139.

16. Kobayashi, T., Nakayama, T. \& Kitamura, M. (1978) Clin. Chim. Acta 86, 261-265.

17. Crofton, P.M. \& Smith, A. F. (1978) Clin. Chim. Acta 83, 235-247.

18. Yuu, H., Takagi, Y., Senju, O., Hosoya, J., Gomi, K. \& Ishii, T. (1978) Clin. Chem. 24, 2054-2057.

19. Rapaport, E. (1975) Cardiovasc. Res. 9, 473.
Dr. Jürgen Bohner Dr. Dr. Wolfgang Stein Medizinische Klinik, Abt. IV Otfried-Müller-Str. 10 D-7400 Tübingen 
